\title{
Adaptations to the Covid-19 Pandemic: Open Spaces in Residential Neighbourhoods of Dhaka, Bangladesh
}

\author{
Afrida Afroz Rahman, Zareen Habiba Islam \\ Department of Architecture, University of Asia Pacific, Dhaka, Bangladesh \\ Corresponding Author: Afrida Afroz Rahman; E-mail- afrida@uap-bd.edu
}

\begin{abstract}
The outbreak of COVID-19 has brought the world to a standstill, affecting every aspect of human life. The impact can be felt more vehemently in cities, where economic activities have slowed down and people are forced to be confined within the four walls of their homes because of prolonged lockdown. The urban open spaces are naturally being underused as they are perceived to be potential hotspots for the outbreak, while the need for open spaces within the houses and the buildings are immensely felt. To cope with this need, people seem to be using the available open spaces within their houses and their buildings like verandahs, roofs, parking spaces etc. In a highly dense and heavily built up city like Dhaka, where open spaces in both house and community scale is already scarce, it is imperative to see how people are fulfilling their needs for open spaces during this pandemic. Dhaka having both planned and organically grown residential neighbourhoods, provides a chance to study whether these two are coping with the pandemic situation similarly or differently. The objective of this paper is to explore the use and the modification of open spaces within the housing units and the buildings during the pandemic. This paper focuses on how the need for the use of open spaces has changed and how people are fulfilling their spacebased interactions. To develop a comprehensive understanding, this paper focuses on both formal and organically grown neighbourhoods of Dhaka city. Due to the potential risk inherent in physical survey, primary data was collected through online questionnaires and semi structured interviews.
\end{abstract}

Keywords: Pandemic, Open Space, Social Interaction, Social Space, Neighbourhood, Dhaka

\section{Introduction}

"Stay Home, Stay Safe", has been the slogan for the year 2020 with the outbreak of COVID-19 pandemic. Also known as the coronavirus pandemic, it is caused due to severe acute respiratory syndrome coronavirus 2 (SARS-COV-2) (Xu et al., 2020, WHO 2020), was first identified in December 2019 in Wuhan, China. It eventually spread in many countries all over the world (Huang et al. 2020, Jiang et al., 2020; Lipistch et al., 2020). An outbreak of Public Health Emergency of International Concern was declared by World Health Organization on January 30 and by March 11 it was a pandemic. According to COVID-19 Dashboard by the Centre for Systems Science and Engineering (CSSE) at Johns Hopkins University (JHU), as of September 
15, 2020, more than 29 million cases of COVID-19 have been reported in more than 188 countries and territories, resulting in more than 926,544 deaths and 16.4 million people recovered.

The virus was confirmed to have spread in Bangladesh in March 2020. Institute of Epidemiology, Disease Control and Research (IEDCR) reported the first three known cases on March 8 with the number increasing with time identifying Bangladesh to be the second most affected country in South Asia. To keep the spread of corona virus in control, many countries took different measures and surveillance tools like temporary closure of educational institutes, shopping complexes, restaurants, prohibiting public events, imposing work from home and maintaining a social distance. The Government of Bangladesh, like many other countries such as China, Italy, Spain, and India enforced social distancing by imposing a lockdown in the country. This lockdown situation forced people to stay at home and attain their regular works like office, school and universities online from home. Dhaka, one of the most densely populated cities with a population of 17 million (Amin, 2018) is also trying to fight the pandemic situation accordingly.

Dhaka, like many other cities has gone through a process of changes and adjustments witnessing imprints of socio-cultural, geo-climatic, technological and economic influences in its growth pattern. Two distinctive types of spatial formations of neighbourhoods are seen in the pattern of Dhaka; the organically grown and the planned. The planned neighbourhoods are laid out in gridiron pattern; plots with designated amenities and facilities and are identified to be more convenient in terms of Wide Street, housing standards, community facilities, open space and amenities. On the contrary, organic neighbourhoods are often seen to have irregular shaped plots with buildings not having enough setbacks. They often lack facilities inevitable for neighbourhood design, like wide streets, footpaths, playfields and shopping complexes in walking distances etc. Informal shops and vendors generally provide the support. In both these types of neighbourhoods, different types of residential buildings are seen. Single-family residences are generally two to three stories and multiple-family residences are generally are more than four stories. Again, there are buildings made by single or multiple owners owned which are popularly known as Individually Developed Apartment Buildings (IDAB), and there are Real Estate Developer built Buildings, more popularly known Real Estate Apartments (REA). The IDAB are generally four to six stories high whereas the REA are up to fifteen floors high depending upon the location. The residential units of these generally are organized against a staircase and a lift lobby having the ground floor and roof as the major shared facilities. The units generally have rooms with common spaces and verandas or balconies are outdoors. Often these verandas are not big enough and face the road or another building next to them.

The current pandemic situation has forced people to stay home and the use of space within the home and the neighbourhood has increased multiple folds than the public urban places. The pandemic situation has affected how people lived, interacted, worked and mostly how people fulfilled their social and emotional needs. Studies on Health and wellbeing focusing on the need of physical and mental health and need for physical exercise and proximity to natural elements and green for wellbeing (Mitra et al 2020, Jacob et al 2020, Alessandro et al 2020, Amerio et al 2020, Sinha et al 2020, Hanzl 2020) is seen. Importance of Housing Research (Rogers and Power 2020) and divisions due to ownership (Peters et al 2020) focuses on research in housing. The changes in the nature of city and neighbourhood (Lai et al 2020, Maccun 2020), impact of COVID19 on public spaces (Roses et al 2020) shed light on the changes in urban scale level. Neighbouring, socializing, and use of the neighbourhood spaces (Glover 2020, Mehta 2020) puts forward how residents have adopted to the neighbourhood level.

As the current pandemic situation has restricted the movement of the inhabitants and most of the time they spend time at home, a question of how they fulfil the need of open space arises. It is observed that the use of roofs and the verandas has increased during the pandemic. Often people are seen to be interacting more with their neighbours than previously in the roof or the ground floor. This paper focuses on how the use of open spaces has changed during the pandemic situation if any, and how people are fulfilling their space-based interactions. A study of different 
types of residential buildings in both the organic and planned areas will also give an opportunity to compare how both the situations are dealing with the pandemic situation.

\section{Theoretical Background}

The outbreak of COVID-19 has resulted in a sudden stop in the overall global pace. As no vaccines or antiviral drugs have yet been approved, non-therapeutic interventions in controlling the spread of the virus are still the most effective way (Bootsma and Ferguson, 2007). Preventive measures like working from home, international travel bans, mandatory lockdown, social distancing etc. are being adopted by many countries to minimize the transmission of the virus. Bangladesh like many other countries is also fighting the battle in its own way. With the first case identified in March 08, between March 9 and September 15, 2020, there were 3,41,056 COVID19 confirmed cases including 4,802 related deaths according to the Institute of Epidemiology, Disease Control and Research (IEDCR). In response to the emergence of the virus, Bangladesh admittedly reduced international flights, imposed thermal scanner checking, and closed down educational institutes. However, offices maintained their regular schedules until March 26. To avoid mass gatherings in order to prevent the spread of the coronavirus in the country, on March 19 , the government instructed the local administrations to stop political and religious rallies, social and cultural gatherings and on March 21, cancelled all state public programs and events, including celebration of the Independence Day. On the March 23, the government announced the closure of all public and private offices from March 26 to April 4 except for hospitals, kitchen markets, drug stores, and other emergency services, which are to remain open. During this period everyone is advised to stay at home and not to go out except for urgent needs such as limited circulation of public transport, limited banking services (WHO 2020). The lockdown has been extended periodically and other than emergency services, most of the offices and institutions are still working from home. Dhaka, being one of the most densely populated cities, (Amin, 2018) is facing the most cases of COVID-19 affected patients and the risk of spreading is also high. Moreover, the complicated nexus of variety of people working throughout Dhaka city from home and physical travel makes a case for studying the overall situation of COVID-19 situation in Dhaka.

Housing being the primary ground where COVID-19 is experienced (Garber, 2020) the experience of home and in home is probably to be impacted the most in the present situation (Rogers and Power, 2020). As staying at home or quarantining (Hang, 2020; Ren, 2020) and social distancing (Ricco, 2020) have been the key measures, the issue of becoming socially disconnected along with experiencing home differently becomes important. Work life balance, mental and physical health, daily routine of life, family time, household chores etc. became more primary concerns during the pandemic lockdown. With the benefits of work from home like saving travel time, having intermediate breaks, avoiding dressing up etc. (Liang, 2020), few serious drawbacks like work life balance, mental health issues, gender role at home etc. are also seen (Ahsan, 2020). The 24/7 digital connectivity has overlain the boundary of office and home time and work meetings are inevitably carried on any time of the day even for an unlimited duration. A survey by Entrepreneur magazine showed that remote workers were likely to clock an additional 60 hours a month as a result of Covid-19 in the USA. A similar online survey on working women in Bangladesh conducted by the Bangladesh Institute of Governance and Management (BIGM) with the objective of understanding the impact of Covid-19 on the professional and personal lives of working women during the lockdown came up with the responses of personal life being affected (Ahsan, 2020). The World Health Organization has recognized that increase anxiousness, anger, stress, agitation and withdrawal might result due to measures like lockdown and social distancing (WHO, 2020). Recent research has shown that levels of poor mental health are high during COVID-19 related social distancing (Jacob et al, 2020; Smith et al, 2020). It is expected that the psychological fallout of the Covid-19 pandemic will be felt for some time and to have a balanced mental health and wellbeing. Moderate to physical activities, balanced diet, proximity to open 
space and nature, communication with people are few of the mediators (Jacob et al, 2020; Alessandro et.al, 2020).

Various studies have documented that the level of exposure to natural environments affect the physical and mental health for all age groups both in indoor and outdoor spaces (Thompson, 2013; Wilkie et al, 2018, cited in Alessandro 2020; Amerio, 2020; Collado et al, 2017). There are even studies that show that interacting with natural elements or even looking at them improves attention, reduces stress and is beneficiary for mental health and wellbeing (Roe et al, 2013; Tennessen, 1996; Thompson, 2012; Jo et at, 2019 cited in Alessandro, 2020). The confinement at home due to the COVID-19 situation has raised the question of if having a view of the natural element like green, sky, water etc. or even growing plants in the home could contribute to wellbeing and mental health (Jacob et al, 2020; Alessandro et.al, 2020). Besides being close to nature, one more thing that becomes important is that the housing situation needs to satisfy different needs which grew in this pandemic situation. The multi-family housing like apartments and condominiums probably need the most flexibility as they are shared by a large number of people compared to a single-family residence. The common shared spaces like roof, ground floor, and open spaces in other levels can become the most flexible space for the residents to use for day-to-day activities and interaction (Alessandro et.al, 2020; Islam 2018). Issues like residential division between the house and the flat and between those who own them and those who do not is compounded by a great spatial divide (Peters, 2020), and these issues might have impact on people's access and frequency to use the shared spaces.

The relationship between the distances of human beings that determines the range of social behaviour is seen in the works of Edward T Hall. In his book "The Hidden Dimension", Hall (1966) defined four scales of distances between people: intimate (less than 1.5 feet - shared with close ones), personal (1.5 to 4 feet - shared with friends and family), social (4 to 12 feet - shared with acquaintances) and public (12 to 25 feet and more - shared with all). Similarly, the space a person needs to fulfil his social needs within home-private and urban-public scenario is hierarchical in character: private, which can be related to the intimate distance within home; contact at door steps, relates to personal distance; neighbourhood level, relates to social distance and finally urban level or public distance (Chermayeff and Alexander, 1963; Correa, 1989). Social distancing thus implies that a person needs to maintain a distance and not bring people to the personal scale. Public space being out of bound during the pandemic situation leaves the spaces within the neighbourhood and within the building for fulfilling people's social needs. In a study on low-density neighbourhoods in USA, Vikas Mehta found that a new proxemics is showing up, as people are tending to use their immediate neighbourhood space more and interact with the acquaintances and neighbours more (Mehta, 2020). But the question remains that what happens to the densely built neighbourhoods and how people fulfill their need of social space. Moreover, most of the educational institutes being closed, children and young people are being confined within the house and the pattern of their activities both physical and sedentary affects their mental health (Mitra et.al, 2020). The similar situation is applicable for elderly people as well.

Dhaka, one of the oldest and major cities in the history has grown from a small trading centre to a large metropolis. Advancement in technology, transportation and communication, and construction section not only reflects in the physical character of Dhaka but also has an enormous effect on the life of its inhabitants. Organic growth in different areas reflects the inherent growth pattern of Dhaka since the Pre-Mughal and Mughal era. The close knit similar professional based neighbourhoods of Dhaka saw its first planned development during the British rule in the form of government colonies and Wari. The planned development kept growing in Dhaka as the administrative centre for East Pakistan though the organic development kept growing side by side. Dhaka became the hub of development as it became the capital after independence. The city with a high density of 1521 person per kilometre (BBS, 2016) is growing in a high rate creating a huge demand for housing and physical infrastructure. Several new satellite towns, residential areas are laid out and many more are on their way. The planned areas are laid out in a grid-iron pattern 
following a masterplan with designated plots for residences, community facilities, open space and amenities. These neighbourhood generally have facilities inevitable for neighbourhood design, like wide streets, footpaths, playfields, shopping complexes in walking distances etc., with designed in the western/universal concept following a typical module of perfect neighbourhood. Many of these perfect neighbourhoods are seen to be not working as expected and turning into mixed used and unplanned state to serve the local needs (Khan, 2008). Small shops, hawkers, temporary food stalls, vans etc. various types of informal solutions are seen to be growing to support the daily needs. Many of these planned neighbourhoods are debated to be liveable in terms of basic amenities, walkability, proximity to amenities compared to the organic neighbourhoods (Satu and Chiu, 2017) though the socio-cultural aspects have not been clearly depicted. Besides these planned developments, lands owned by private ownership are developing in a spontaneous manner by accommodating taller buildings in recent time. The organic areas of Dhaka are growing in its own pace.

In terms of Residential built forms, both single family and multiple family residences are seen in both planned and organic neighbourhoods. Amongst the multiple family residences, owner built buildings and real estate apartments are more popular. The owner built residences are mentioned as Individually Developed Apartment Buildings (IDAB), and Real Estate Developer built Building are mentioned as Real Estate Apartments (REA) this study. The IDAB are generally four to six stories high whereas the REA are up to fifteen floor high depending upon location. Study on the apartments show that a heterogeneous group of people from different socio-economic background are seen to be living in these apartments which gives rise to a new kind of heterogeneous neighbourhood, contrary to what was traditionally seen in homogenous Government colonies which were the early prototypes for apartment living (Hussain, 2010). Both Owner and Tenants are seen in these apartments. The residential units of these are generally organized against the staircase and lift lobby having the ground floor and roof as the major shared facility. The units are generally seen to be having rooms with common spaces and verandas or balconies are outdoors. Often these verandas are not big enough and face the road or another building beside. Among the shared facilities, roof and the ground floor level are seen to be used by most of the residents for meeting their need for social interaction. Again stairs cases besides an open space are also places for interacting (Islam, 2012). Though the extent of use and social interaction changes with time and often depends upon the socio-demographic profile of the users (Islam, 2018).

\section{Methodology}

The paper depends on both primary and secondary data. Secondary data is used to understand the nature of the COVID-19 pandemic, the government's response in trying to contain the spread of the virus and its effect on people's lifestyle. Secondary data collected from books, journal papers, and research papers also help to establish the need of open spaces for interaction and mental health. The types of open spaces in different scales of spaces such as within the neighbourhood, within the building and the apartment as well as the types of residential buildings are identified through secondary data which establishes the parameters for collecting and analyzing primary data.

Respondents from the planned neighbourhoods are located in Mirpur, Uttara, Baridhara, Lalmatia, Dhanmondi, Bashundhara, Mohammadpur and Gulshan 2. In the case of organic neighbourhoods, respondents live in Gopibag, Siddeshwari, Keraniganj, Adabor, Bashabo, Eskaton, Azimpur, Malibag, Tollabag, Khilgaon, Rampura, Moghbazar, Farmgate, Mugda, Badda. 


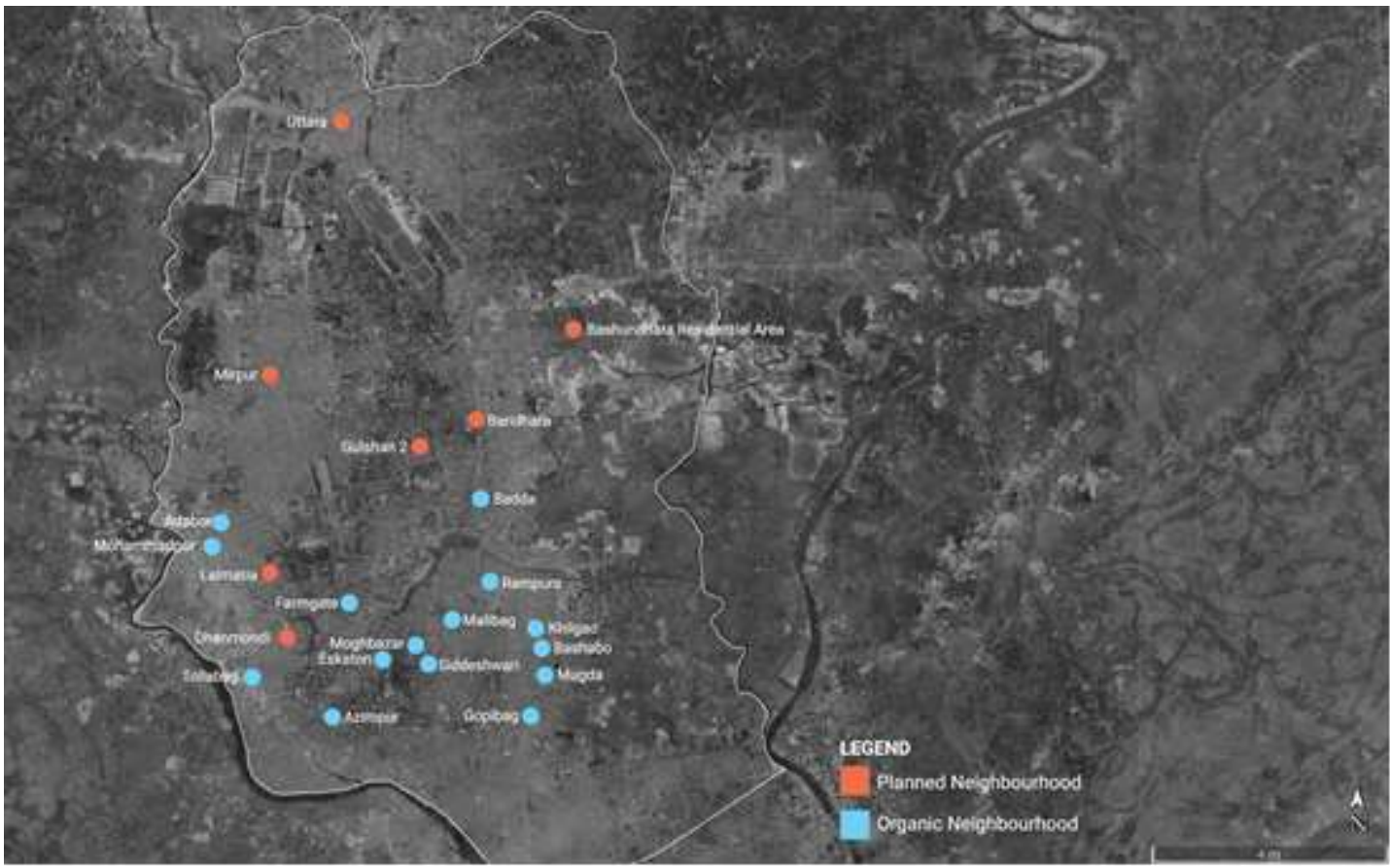

Fig. 01: Selected Residential Neighbourhoods (Source: Google maps with annotation by authors)

Due to the potential risk inherent in a physical survey, primary data was collected through online questionnaires and semi structured interviews. The respondents of the survey were chosen by a random sampling method and an online Google form was used to collect the data. The Google form was circulated in several online social media platforms. The questionnaire form had a total of 62 responses, but 8 of those responses were discarded as the respondents did not answer all of the questions in the form.

The questionnaire was elaborate and had four sections. The first section intended to understand the demography of the samples in terms of, age, gender, family type, household number, occupation, neighbourhood type, residence type, detail of residences and tenure type. The next two sections questioned about the variety and extent of use of space and interactions within the neighbourhood and within the building prior to and during the pandemic situation to understand the changes taking place. And the last section tried to find out the adaptation and changes within the residential unit. Besides questionnaire survey, semi-structured interviews were conducted in order to develop a more comprehensive understanding of the space use in relation to type of housing, neighbourhood and family and tenure status. To avoid the risk inherent in faceto-face interviews, the interviews were conducted using online platforms. For the convenience of collecting information and comparison between pre-pandemic and post-pandemic lifestyles, familiarity with the cases has also informed the selection process. Due to time constrains and unavailability, four cases could be interviewed. 


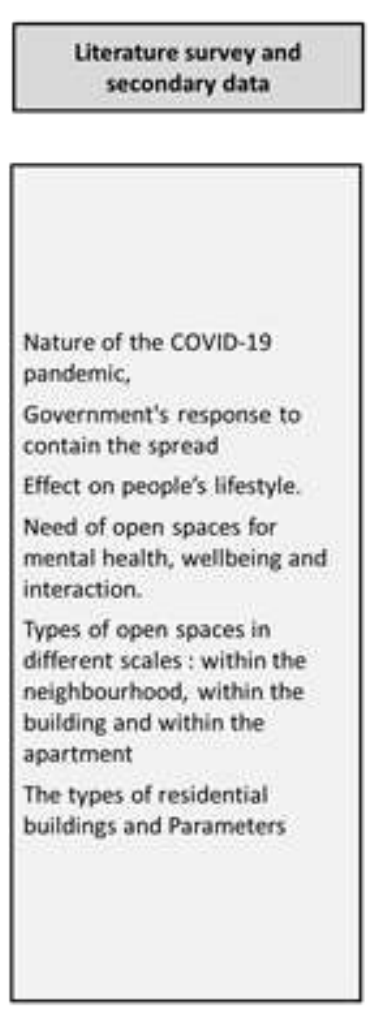

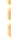

Primary Data through Online Questionnaire Survey and Semi-Structured Interview

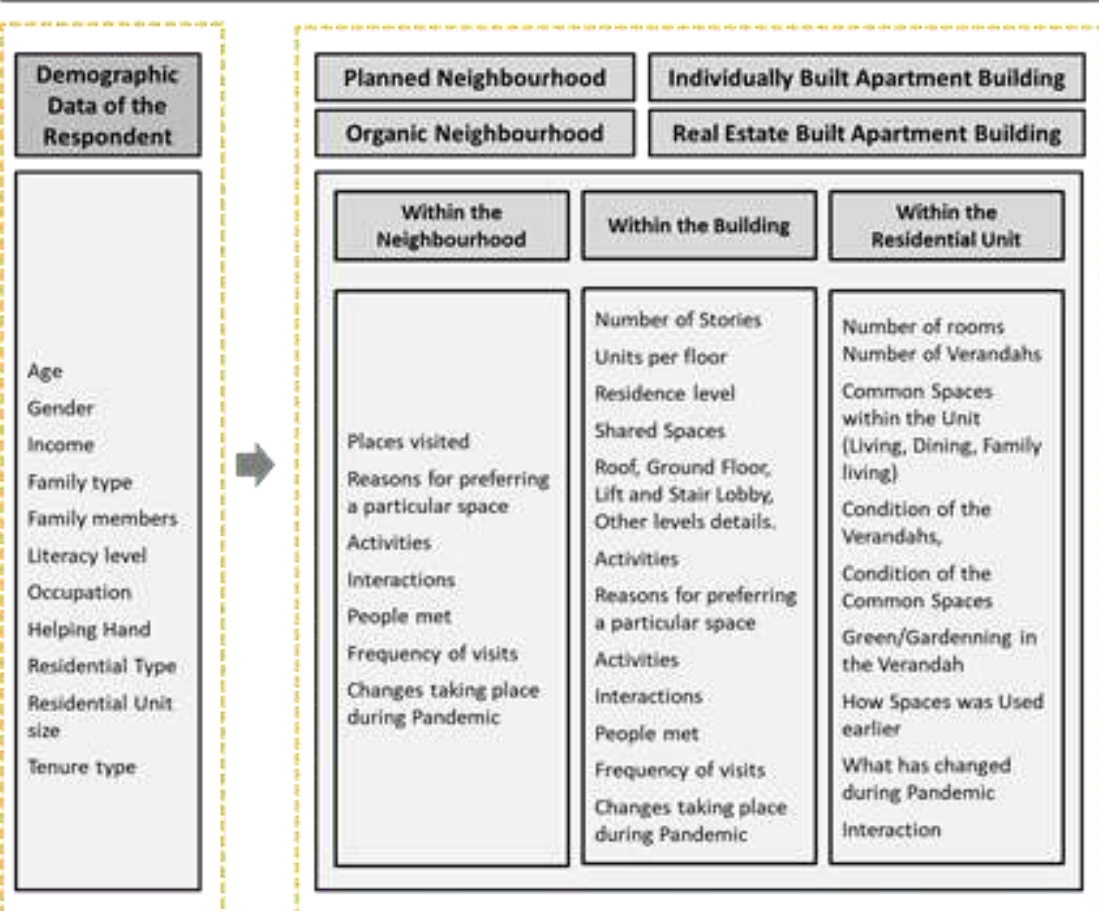

Fig. 02: Method and Criteria of Data Collection Source: Author

\section{Data Analysis and Findings}

\section{Respondents' Profile}

54 respondents participated in the online questionnaire survey. Out of the 54 respondents, 26 are female and 28 are male. 19 out of the 54 respondents have at least 3 other members in their family. 29 respondents are from planned neighbourhoods whereas 25 of the respondents live in organic neighbourhoods. The respondents predominantly live in 5-8 storied buildings (51.9\%) and these buildings can be broadly categorized into three groups such as Real Estate built apartment building, individually developed apartment building and single-family residence.

\begin{tabular}{lll} 
Parameters & Range & No. of Respondents \\
\hline \multirow{3}{*}{ Gender } & Male & $28(51.9 \%)$ \\
& Female & $26(48.1 \%)$ \\
& Other & $0(0 \%)$ \\
\hline \multirow{3}{*}{ Age } & $21-25$ & $5(9.3 \%)$ \\
& $26-30$ & $18(33.3 \%)$ \\
& $31-35$ & $5(9.3 \%)$ \\
& $36-40$ & $14(25.9 \%)$ \\
& $41-45$ & $2(3.7 \%)$ \\
Household Size & $46-50$ & $5(9.3 \%)$ \\
& Above 50 & $5(9.3 \%)$ \\
\hline & 2 & $7(12.7 \%)$ \\
& 3 & $16(29.2 \%)$ \\
& 4 & $19(34.5 \%)$ \\
& 5 & $7(12.7 \%)$ \\
\hline
\end{tabular}




\begin{tabular}{lll} 
& $6-9$ & $6(10.9 \%)$ \\
\hline \multirow{3}{*}{ Occupation } & Professional & $18(32.7 \%)$ \\
& Academician & $10(18.2 \%)$ \\
& Student & $7(12.7 \%)$ \\
& Govt. Service & $9(16.4 \%)$ \\
& Private Service & $7(12.7 \%)$ \\
& Business & $2(3.6 \%)$ \\
& Homemaker & $2(3.6 \%)$ \\
\hline \multirow{2}{*}{ Neighbourhood Type } & Planned & $29(53.7 \%)$ \\
& Organic & $25(46.3 \%)$ \\
\hline \multirow{3}{*}{ Housing Type } & Single family residence & $8(14.8 \%)$ \\
& Real-estate built apartment building & $23(42.6 \%)$ \\
& Individually developed apartment building & $23(42.6 \%)$ \\
\hline \multirow{3}{*}{ Building Height } & 1 storeyed & $0(0 \%)$ \\
& $2-4$ storeyed & $9(16.7 \%)$ \\
& $5-8$ storeyed & $28(51.9 \%)$ \\
& $8-10$ storeyed & $13(24.1 \%)$ \\
& $11+$ storeyed & $4(7.4 \%)$ \\
\hline \multirow{2}{*}{ Apartment Size } & Below 1000 SQFT & $5(9.3 \%)$ \\
& $1001-1200$ SQFT & $11(20.4 \%)$ \\
& $1201-1400$ SQFT & $8(14.8 \%)$ \\
& $1401-1600$ SQFT & $6(11.1 \%)$ \\
& $1601-1800$ SQFT & $7(13.0 \%)$ \\
& $1801-2000$ SQFT & $4(7.4 \%)$ \\
& Above 2000 SQFT & $13(24.1 \%)$ \\
\hline
\end{tabular}

Fig. 03: Respondents' Profile Source: Author

\section{Use of Space and Activities within the Neighbourhood}

Even prior to the pandemic, $21 \%$ of the respondents from the organic and $20 \%$ of the respondents from the planned neighbourhoods did not visit anywhere within the neighbourhoods. This percentage increased to $24 \%$ in organic neighbourhoods whereas in planned neighbourhoods, it increased to $41 \%$ meaning twice as many people have stopped using the neighbourhood open spaces.

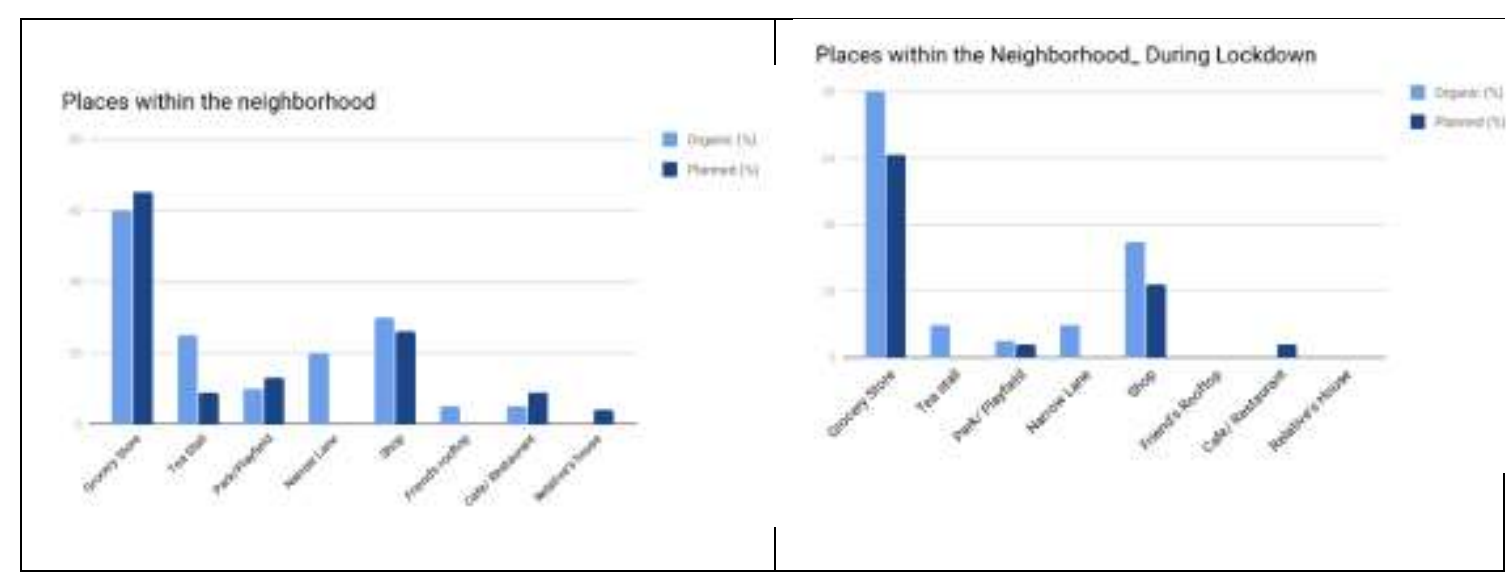




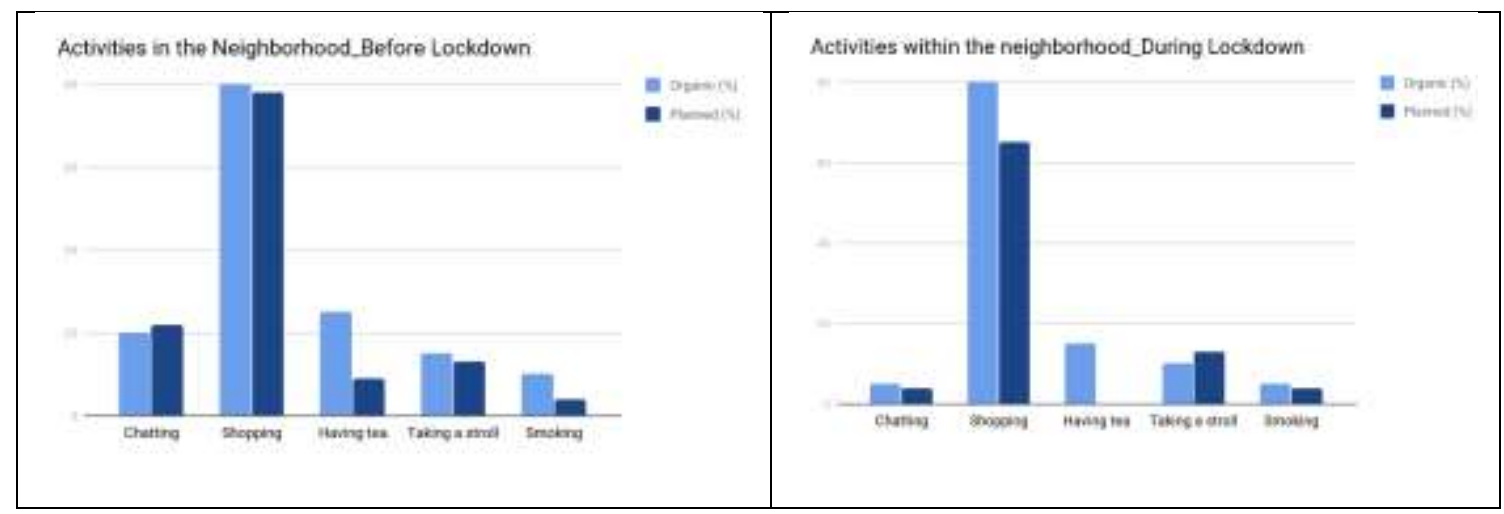

Fig. 04: Comparison between use of space within the neighbourhood pre and post lockdown Source: Author

As can be seen from the charts above, grocery stores are the most visited places within the neighbourhood in both pre and post-pandemic situations. In fact, grocery stores were more used by respondents in the post-pandemic period in the case of organic neighbourhoods. Places in organic neighbourhoods are visited by more people than in planned neighbourhoods with the exception of grocery stores, playfields and cafes. In the post-pandemic period, social interaction reduced more significantly in planned neighbourhoods compared to that in organic neighbourhoods. Most of the social interaction takes place in narrow lanes, tea-stalls and cafes along with some chance encounters in grocery stores and shops.

Grocery shopping is predominantly done by men in both the pre and post pandemic period (61\% before pandemic and $67 \%$ after pandemic). Women in general do not use neighbourhood spaces as much as men. For example, $0 \%$ of the tea-stall users are female, only one out of the five respondents visiting the playfields prior to the pandemic is a female. Only $25 \%$ of the narrow lane users are female, and the number dropped to $0 \%$ in the post pandemic period. In general, the indoor neighbourhood spaces such as cafes/ restaurants are not used as much as the outdoor spaces, and are predominantly used by women. In the post pandemic period, women's already limited activities within the neighbourhood have also reduced to only shopping for groceries and other daily necessities. Most of the respondents prefer these spaces due to their proximity to their residences.

One respondent from the planned neighbourhood of Uttara noted that she still visits the neighbourhood cafe for socializing because it is "close to my house and also following the protocols for COVID 19." Another mentioned that he can interact with neighbors when he spends time in the park. One mentioned that his friends meet him at a shop for socialization.

In organic neighbourhoods, three respondents mentioned that they are still using narrow lanes and tea-stalls for interaction with their friends. One respondent mentioned that he meets friends in front of the grocery store. They mostly meet their friends or neighbours and sometimes come across some acquaintances. In response to the question of how these neighbourhood spaces can be improved or made more usable, most of the respondents raised the issue of maintaining proper social distancing and other safety and hygiene measures.

The findings from the interviews reaffirm the finding of the online survey that there seems to be more social interaction in organic neighbourhoods than in planned neighbourhoods. For example, multiple family members of Respondent D (her husband, brother-in-law, and nephew) had friends in the neighbourhood with whom they would spend time in shops, and in alleys. Respondent $\mathrm{C}$ also interacted with his neighbours near his house. However, in the case of planned neighbourhoods, both respondents $\mathrm{A}$ and $\mathrm{B}$ reported no interaction in the neighbourhood level.

In both neighbourhoods the most visited places within the neighbourhoods are grocery stores or super shops. But three out of the four respondents reported a decrease in the number of 
visits to the grocery store in the post-pandemic period as all of them have turned to online shopping.

\section{Use of Space and Activities within the Building}

Open spaces within the building such as rooftop, staircase and lift lobby, attached play spaces, etc. are used the most in real estate built apartment buildings. These spaces are being used by fewer respondents in the post-pandemic period in all types of residential buildings. This decrease in the number of users can be attributed to the fact that elevators and lobbies are seen as potential hotspots for spreading coronavirus and hence resulting in fewer people using the lobby spaces and the rooftops. This is corroborated by the interviews of Respondents B, C and D. B and $\mathrm{D}$ occasionally visited their rooftops while $\mathrm{C}$ used to visit the rooftop at least once every week prior to the pandemic, but all of them stopped going to the rooftops in the post-pandemic period out of apprehension against using elevators. In case of Respondent B and D, landlords have also imposed restrictions on using rooftop in the post-pandemic period. However, reservations against using elevators did not stop respondent A from using her rooftop, who goes there in the morning to water her new plants and also in the evening when she interacts with her neighbor and her son plays with kids of similar age.

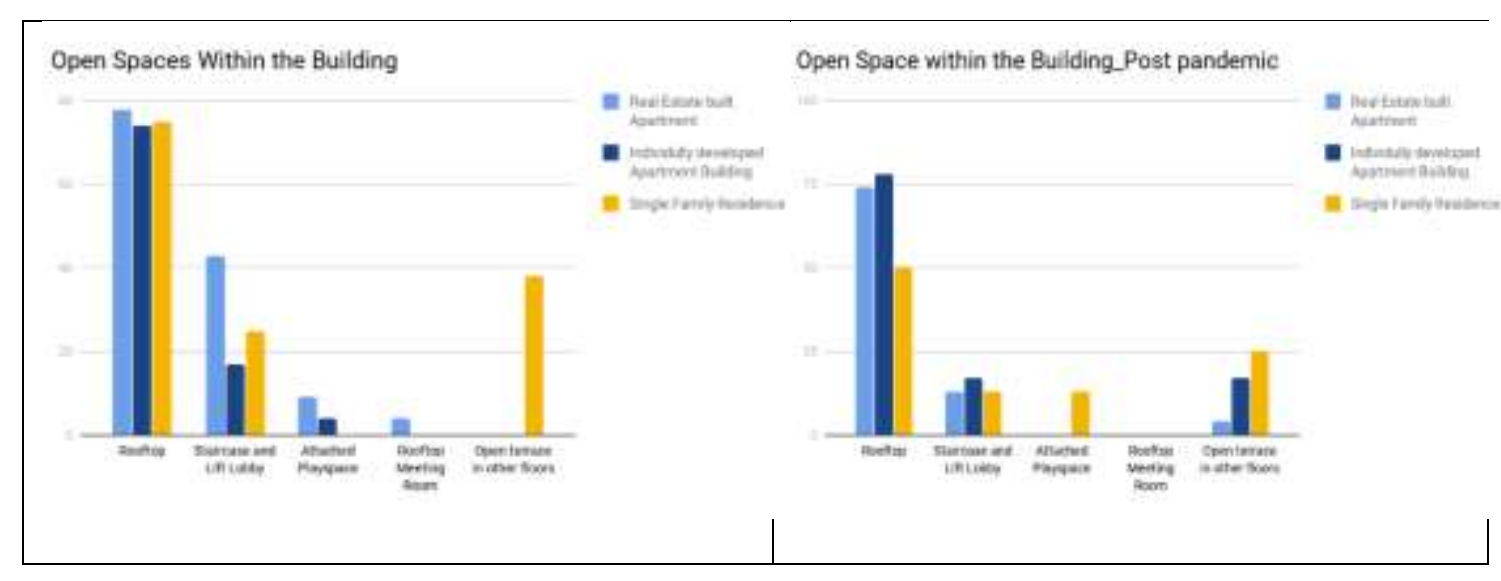

Fig. 05: Spaces within the Buildings

Source: Author

Prior to the lockdown, open spaces within the building were mostly used for drying clothes, respondents also listed activities such as morning/evening walks, gardening, playing, having tea, flying kites and smoking. In most cases, respondents from Real Estate built apartment buildings and single family residences seem to be more involved in such activities. Prior to the pandemic, gardening and having tea in the open spaces within the building seemed to be done mostly by women ( $61 \%$ of gardening and $65 \%$ of having tea is done by female respondents). Other activities are done by both male and female in nearly equal ratio. 


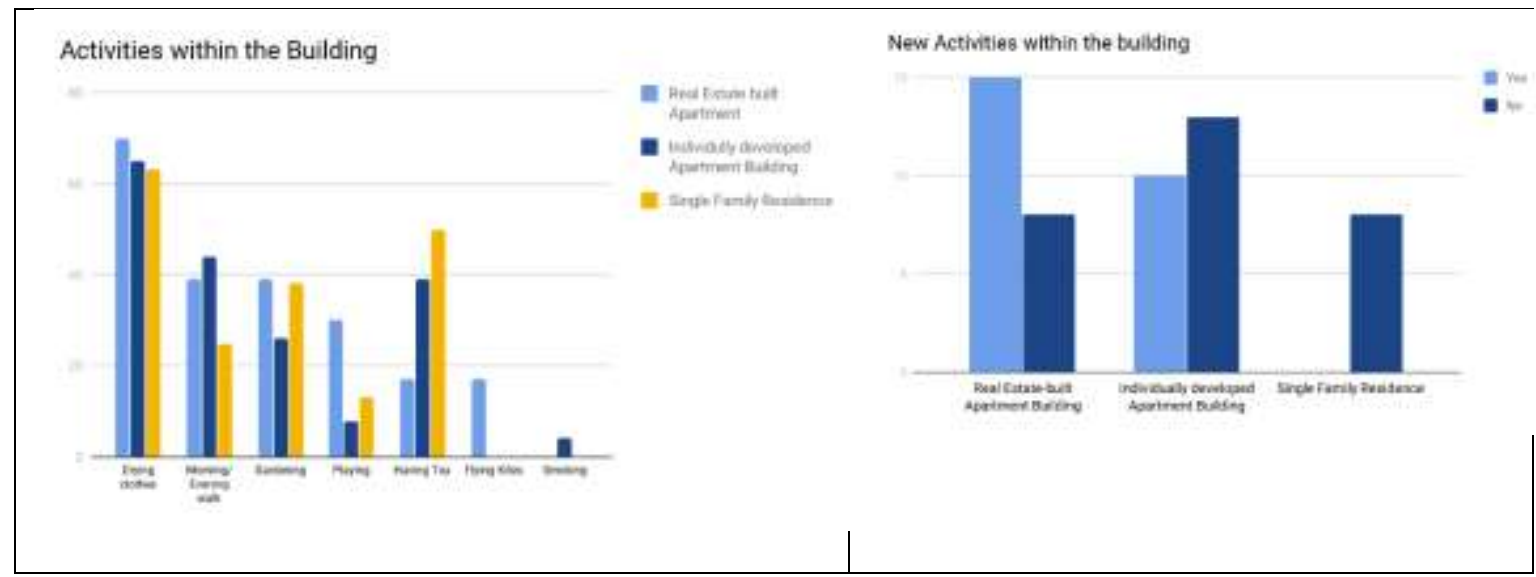

Fig. 06: Activities and Spaces within the Buildings

Source: Author

During the lockdown, 25 out of 54 respondents mentioned they started doing new activities in the open spaces within the building, majority of them live in Real Estate built apartments. Gardening is the most popular new activity during the lockdown as 7 out of 25 respondents have mentioned that they have started gardening during this pandemic. Four of the respondents mentioned that they have started doing exercise in their open spaces and three others have mentioned that they started having walks around the open spaces. Some have taken up new hobbies such as playing guitar, flying kites and swimming and playing. One respondent mentioned interaction with family members and two mentioned that they use these open spaces for simply relaxing. Respondents generally seem to use these places more in the latter half of the day, evening being the most popular choice as chosen by $44 \%$ of the respondents and afternoon being chosen by $30 \%$ of the respondents. Rest of the respondents prefer mornings.

Although there are fewer respondents using these open spaces in the post pandemic period, those who are still using these spaces spend a longer period of time in these spaces. $64.3 \%$ of respondents mentioned that they spend an increased amount of time in these open spaces in the post pandemic period. $65.5 \%$ of the respondents spend 30 minutes to 2 hours in these spaces.

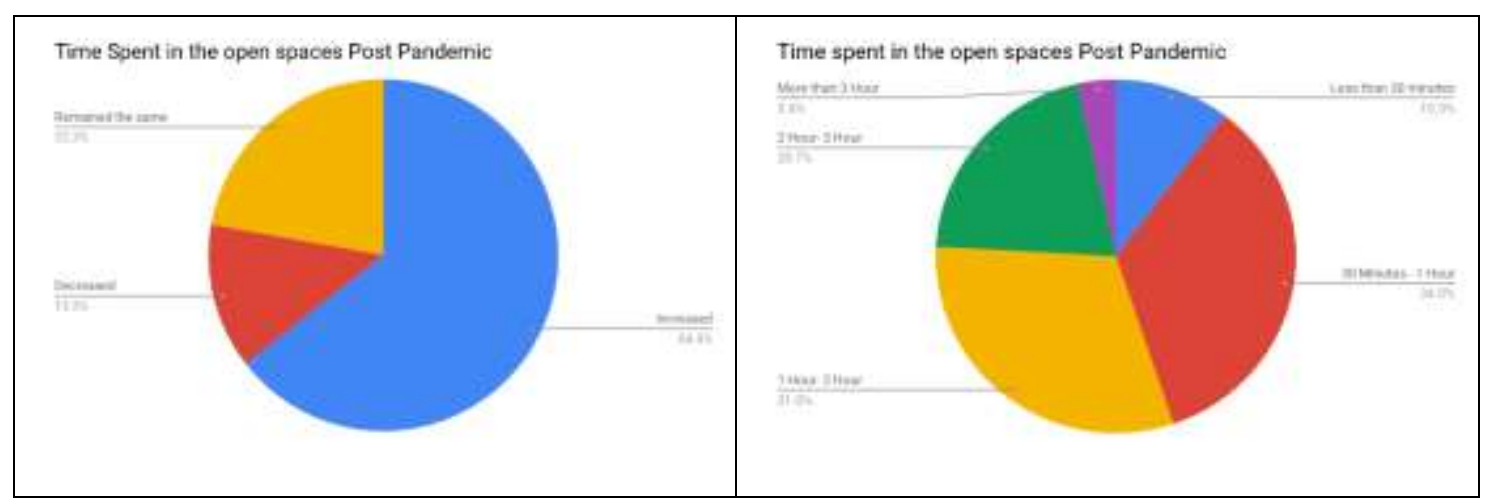

Fig. 07: Time spent in the Building Source: Author

To develop a better understanding of social interaction in the open spaces within the buildings, data was collected from the interviews. Prior to the lockdown, respondent $\mathrm{D}$ had regular interaction with the residents of her building in the lift lobby on the ground floor while taking her kids to school, which has stopped after the lockdown. A decrease in social interaction has also 
been reported by respondent $\mathrm{C}$, who used to interact with his upstairs neighbor in the ground floor of his building prior to the pandemic and cannot do so now. Respondent B mentions no change in the already non-existent interaction with his neighbors. Only respondent A confirms an increase in social interaction within the building which has been brought upon by regular visits to the rooftop. It is also interesting to note that out the three tenants, two (Respondent B and D) faced restrictions from their landlord against going to the roof while respondent A, who is the owner of her apartment, has uninterrupted access to the rooftop.

\section{Use of Space within the Apartment}

As people are forced to spend most of their time indoors, spaces within the house are being used more due to the pandemic. As people are working from home, their space preferences are being influenced by work related factors. For example, bedrooms and study are being used as home offices. People are also spending more of their free time with their family and the most popular family activity is watching TV. $20 \%$ of the respondents said they watch more TV with their families.

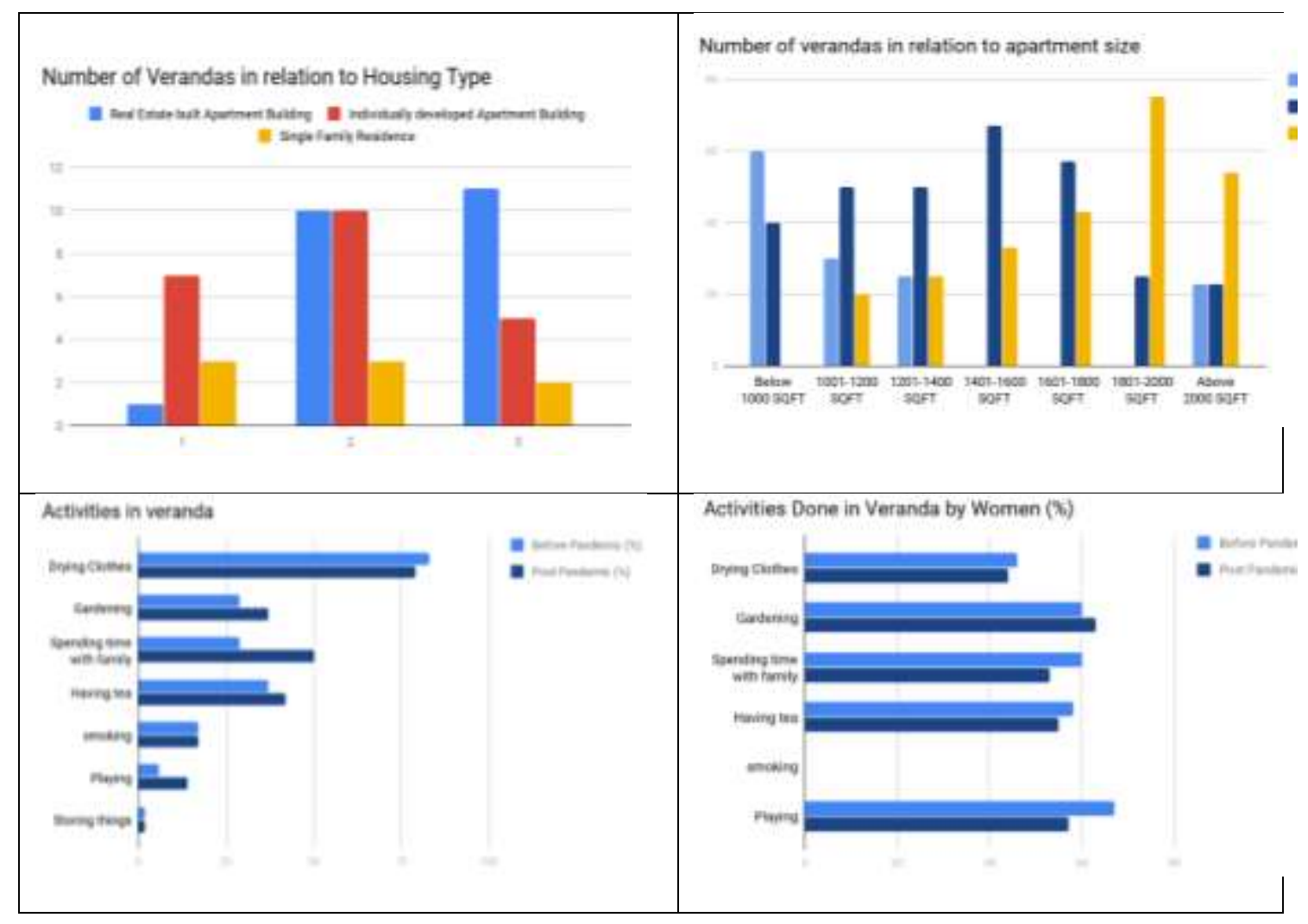

Fig. 08: Verandah within the building and their use

Source: Author

Apartments below 1000 sq. ft. mostly have one or two verandas. But with increase of apartment size, the instance of the apartments having one veranda is reduced and the numbers of apartments having two and three verandas increase. Apartments above 1400 sq. ft only have two or more verandas, whereas in case of apartments above 1800 sq.ft, there are more apartments with three verandas than there are apartments with two verandas. 55\% of the respondents from Real Estate built apartment buildings do not have enough space to do leisure activities in their verandas, whereas this percentage is $50 \%$ in both individually developed apartment buildings and single family residences. It can be seen from the chart that, Real Estate built apartments have a larger 
number of verandas but these verandas seem to be smaller in size. In general, $63 \%$ of the respondents have plantations in their veranda.

It can be deduced from the charts that in planned neighbourhoods, verandas offer greater views. But in general, the views are dominated by other buildings in both types of neighbourhoods. This can be attributed to the fact that buildings in planned neighbourhoods strictly adhere to the setback rules, which provides the inhabitants with bigger apertures between buildings and hence, a greater view angle than the buildings in organic neighbourhoods. The use of verandas has increased in the post-pandemic situation. Respondents seem to be spending more time with their families in the verandas during the lockdown. In general, verandas seem to be used more by female members of the family, activities such as gardening, spending time with family members and having tea are done mostly by female respondents. However, men started using verandas more often than before during the pandemic, as can be seen from the reducing percentage of female engagement in activities in the verandas. Smoking seems to be exclusively done by men.

Information from the interviews depicted how various spatial and climatic factors influence the use of verandas. For example, the width and orientation of the veranda, amount of sunlight received, weather and climate influence the use of the veranda. Although respondent A spends 30 minutes to one hour in the morning tending to her plants in the south-facing veranda, she complains that the heat and glare maked it hard to use during the rest of the day. She predicts that

"I might spend more time here (in the veranda) in the winter when the sunlight won't be too strong, now the heat and glare is just too unbearable...". She also complained about the small size of the veranda which has limited its use"

(Respondent A).

However, the situation is not the same for respondent B, C, and D. Despite having enough space in the veranda, respondent $\mathrm{B}$ and his family use the verandas only for hanging clothes. $\mathrm{B}$ attributed the heat and glare coming from the south as well as the water accumulated in the floor from drying clothes as the main reasons for the verandas not being used in both pre and post pandemic period. While respondent $\mathrm{B}$ resents the glare in the veranda, respondent $\mathrm{C}$ describes the opposite scenario and blames the lack of sunlight in his veranda for limiting its use. This insufficient amount of sunlight is caused by the veranda's orientation towards north and the close proximity of adjacent buildings. But he did mention increased use of this space as during the lockdown, he started spending time with his 8-month old daughter in the veranda who enjoys the view of the lane. $\mathrm{C}$ can also interact with his neighbor's child through the veranda due to the proximity of the neighboring building. Respondent $\mathrm{D}$, despite having five verandas, can use none of the verandas for any purpose other than drying clothes because of their insufficient depth and the placement of the outdoor unit of the air conditioning device. Only one veranda which is connected to the living room was used for gardening even prior to the pandemic, an activity which is still being continued during the pandemic.

\section{Children and Elderly People During Pandemic}

In the case of planned neighbourhoods, $30 \%$ of the families with children have kids who do not use any kind of open space inside or outside the building, whereas in organic neighbourhoods the number is slightly higher and is at $37.5 \%$. But it can be seen that the children from organic neighbourhoods use not only the open spaces within the building more than the children from planned neighbourhoods, some of them also have gone outside the building where the number is zero in the case of planned neighbourhoods. Veranda and rooftop are the most used spaces for children during the pandemic.

In the case of elderly members, organic neighbourhoods seem to be more elderly peoplefriendly as open spaces both inside and outside the building are used more by the elderly people in organic neighbourhoods than in planned neighbourhoods, with the exception of rooftops. In 
organic neighbourhoods, rooftops are less used by elderly members; the lack of elevators in buildings in organic neighbourhoods, as well as reservations against using elevators in postpandemic situation, may have contributed to this phenomenon. In organic neighbourhoods, verandas are preferred by more elderly persons.

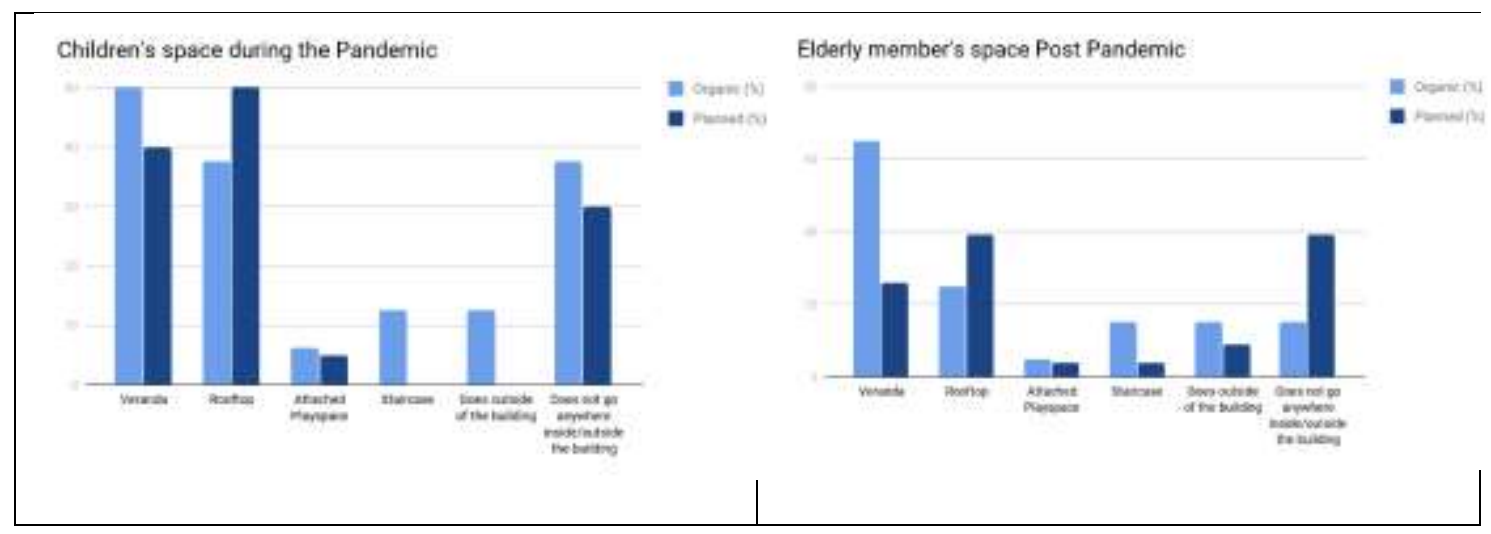

Fig. 09: Children and Elderly during pandemic Source: Author

\section{Discussion and Conclusion}

This paper was a small attempt to understand how people in different neighbourhoods and house types are adapting to the COVID-19 Pandemic. Though the number of samples are not large enough for establishing any conclusion, a wide range of activities and variants are seen. It is evident that the use of open space and social interaction has indeed decreased during the pandemic, yet the decrease is far more significant in planned neighbourhoods than in organic neighbourhoods. As the growth is spontaneous and informal, the organic neighbourhoods provide more open spaces such as tea stalls, narrow lanes etc. for social interaction. Grocery shopping seems to be the most carried out activity at neighbourhood level and is predominantly done by men. Women use neighbourhood open spaces less than men. The planned neighbourhoods having more formal shopping complexes and ease in online deliveries, respondents are more inclined to go for online shopping rather than visiting physically.

In the case of apartment buildings, open spaces within Real Estate built apartment buildings are more used than in individually developed apartment buildings or single family residences. From interviews, it can be seen that during the lockdown, rooftops have become less accessible due to restrictions imposed by landlords on using rooftops as well as due to the reservations against using elevators. It is seen that, concerns regarding mental health has resulted into various activities within the building during the pandemic situation. Gardening has emerged as the most popular new activity engendered by the excess free time during the lockdown and is mostly done by the residents of Real Estate built apartments. Physical exercise is also incorporated into some respondents' use of open space. These open spaces are used mostly in the latter half of the day, and the amount of time spent in these spaces by the residents have increased in the postpandemic period despite the decrease in number of users. However, from interviews, it was found that all four respondents feel the need for shaded seating in the rooftops.

It was found from the online survey that the number of verandas increases with apartment size, and Real Estate built apartments usually provide a greater number of verandas, although these verandas tend to be smaller. In fact, nearly $50 \%$ of the respondents feel that they do not have enough space in their verandas for leisurely activities. In the post pandemic period, use of verandas has increased significantly and more people are spending time with their families in the verandas 
as well as inside the house. However, from the interviews it was evident that the depth and orientation of verandas, amount of sunlight received, weather and climate greatly influence the use of the verandas.

This paper can thus conclude that spaces in the organically grown neighbourhoods tend to be used more. Again, the spaces within the building in Real estate Apartments are more used due to the ownership pattern and the availability of sufficient space to perform various activities. Spaces within the units depend mostly on the preferences of the user, although physical design, adequate natural light, ventilation and views are influencing factors. Although this paper dives into the search for patterns of use of open space in neighbourhood, building and apartments, a deeper probe is necessary to further the understanding of all the parameters working behind these patterns.

\section{References}

Mitra, R., Moore,S.A., Gillespie, M., Faulkner, G., Vanderloo,M., Bozzer,T., Rhodes, R.E., Brussoni, M., Tremblay,M.S. (2020), Healthy Movement Behaviours in Children and Youth During the COVID-19 Pandemic: Exploring the Role of the Neighbourhood Environment. Health \& Place, 65. Available from: https://doi.org/10.1016/j.healthplace.2020.102418 [Accessed 17 September 2020]

Cantello, Ian \& Mitra, Raktim \& Buliung, Ron. (2016). Children's Activity Lifestyles, Physical Activity Participation and Social-Ecological Correlates in Toronto, Canada. Journal of Transport \& Health, 3. S28. 10.1016/j.jth.2016.05.071.

Xu, Z., Shi, L., Wang, Y., Zhang, J., Huang, L., Zhang, C., et al. (2020). Pathological findings of COVID-19 associated with acute respiratory distress syndrome. Lancet Respir. Med. 8 (4), 420-422. [Accessed 19 May 2020]

World Health Organization. (2020). Coronavirus disease (COVID-19) pandemic: WHO characterizes COVID-19 as a pandemic. Available from: https://www. who.int/emergencies/diseases/novel-coronavirus-2019/events-as-they-happen. [Accessed 23 May 2020]

Jacob, L., Tully, M. A., Barnett, Y., Lopez-Sanchez, G. F., Butler, L., Schuch, F., López-Bueno, R., McDermott, D., Firth, J., Grabovac, I., Yakkundi, A., Armstrong, N., Young, T., \& Smith, L. (2020). The relationship between physical activity and mental health in a sample of the UK public: A cross-sectional study during the implementation of COVID-19 social distancing measures. Mental health and physical activity, 19, 100345. Available from: https://doi.org/10.1016/j.mhpa.2020.100345 [Accessed 02 August 2020]

D’Alessandro, D., Gola, M., Appolloni, L., Dettori, M., Fara, G.M., Rebecchi, A., Settimo, G., Capolongo, S. (2020). COVID-19 and Living Space Challenge. Well-being and Public Health Recommendations for a healthy, safe, and sustainable housing. Acta bio-medica: Atenei Parmensis, 2020, 91 (Suppl. 9), 61-75.

Amerio, A., Brambilla, A., Morganti, A., Aguglia, A., Bianchi, D., Santi, F., Costantini, L., Odone, A., Costanza, A., Signorelli, C., Serafini, G., Amore, M., \& Capolongo, S. (2020). COVID-19 Lockdown: Housing Built Environment's Effects on Mental Health. International journal of environmental research and public health, 17(16), 5973. Available from: https://doi.org/10.3390/ijerph17165973 [Accessed 17 September 2020]

Ward Thompson, C. (2013). Activity, exercise and the planning and design of outdoor spaces. Journal of Environmental Psychology, 34. 79-96. 10.1016/j.jenvp.2013.01.003.

Wilkie, S., Townshend, T., Thompson, E., \& Ling, J. (2019). Restructuring the built environment to change adult health behaviors: a scoping review integrated with behavior change frameworks. Cities \& health, 2(2), 198-211. Available from: https://doi.org/10.1080/23748834.2019.1574954 [Accessed 02 August 2020]

Roe, J. J., Thompson, C. W., Aspinall, P. A., Brewer, M. J., Duff, E. I., Miller, D., Mitchell, R., \& Clow, A. (2013). Green space and stress: evidence from cortisol measures in deprived 
urban communities. International journal of environmental research and public health, 10(9), 4086-4103. Available from: https://doi.org/10.3390/ijerph10094086 [Accessed 02 August 2020]

Glover, T. (2020). Neighboring in the Time of Coronavirus? Paying Civil Attention While Walking the Neighborhood. Leisure Sciences, 1-7. 10.1080/01490400.2020.1774014.

Rogers, D., \& Power, E. (2020). Housing policy and the COVID-19 pandemic: the importance of housing research during this health emergency. International Journal of Housing Policy, 20. 1-7. Available from: https://doi.org/10.1080/19491247.2020.1756599 [Accessed 02 August 2020]

Hang, M. (2020). Preparing cities for epidemics: lessons from the COVID19 outbreak. International Journal of Urban and Regional Research. Available from: https://www.ijurr.org/the-urban-now/preparing-cities-for-epidemics [Accessed 08 March 2020]

Ren, X. (2020). The quarantine of a megacity: China's struggle over the coronavirus epidemic. International Journal of Urban and Regional Research. Available from: https://www.ijurr.org/the-urban-now/the-quarantine-of-a-megacity/ [Accessed 08 March 2020]

Ricco, J. (2020). For a governmentality of ethical distance. Unbecoming community. Available from: https://unbecomingcommunity.wordpress.com/2020/03/17/for-a-governmentalityof-ethical-distance/ [Accessed 03 April 2020]

Garber, M. (2020). Homes Actually Need to Be Practical Now: One of the ironies of social distancing is that it can put privacy in short supply. The Atlantic March 29. Available from: $\quad$ https://www.theatlantic.com/culture/archive/2020/03/finding-privacyduringpandemic/608944/ [Accessed 11 April 2020]

Jordi Honey-Rosés, Isabelle Anguelovski , Vincent K. Chireh , Carolyn Daher , Cecil Konijnendijk van den Bosch, Jill S. Litt, Vrushti Mawani, Michael K. McCall , Arturo Orellana, Emilia Oscilowicz, Ulises Sánchez, Maged Senbel, Xueqi Tan , Erick Villagomez , Oscar Zapata \& Mark J Nieuwenhuijsen (2020): The impact of COVID-19 on public space: an early review of the emerging questions - design, perceptions and inequities, Cities \& Health, DOI: 10.1080/23748834.2020.1780074

Honey-Rosés, J., Anguelovski, I., Chireh, V., Daher, C., Konijnendijk van den Bosch, C. Litt, J., Mawani, V., McCall, M., Orellana, A., Oscilowicz, E., Sánchez-Sepúlveda, H.U., Senbel, M., Tan, X., Villagomez, E., Zapata, O., Nieuwenhuijsen, M. (2020). The impact of COVID-19 on public space: an early review of the emerging questions - design, perceptions and inequities. Cities \& Health, 1-17.

McCunn, L. (2020). The importance of nature to city living during the COVID-19 pandemic: Considerations and goals from environmental psychology. Cities \& Health. DOI: $10.1080 / 23748834.2020 .1795385$

Collado, S., Staats, H., Corraliza, J. A., \& Hartig, T. (2017). Restorative environments and health. In G. Fleury-Bahi, E. Pol, \& O. Navarro (Eds.), International handbooks of quality-oflife. Handbook of environmental psychology and quality of life research (p. 127-148). Springer International Publishing. Available from: https://doi.org/10.1007/978-3-31931416-7_7 [Accessed 02 August 2020]

Mehta, V. (2020). The new proxemics: COVID-19, social distancing, and sociable space. Journal of Urban Design. DOI: 10.1080/13574809.2020.1785283

Hall, E. T. (1966). The Hidden Dimension. New York: Doubleday.

Sinha, M., Kumar, M., Zeitz, L., Collins, P.Y., Kumar, S., Fisher, S., Foote, N., Sartorius, N., Herrman, H., Atwoli, L. (2020). Towards mental health friendly cities during and after COVID-19. Cities \& Health. Available from: https://doi.org/10.1080/23748834.2020.1790251 [Accessed 16 August 2020] 
Hanzl, M. (2020). Urban forms and green infrastructure - the implications for public health during the COVID-19 pandemic. Cities \& Health, 1-5. Available from: https://doi.org/10.1080/23748834.2020.1791441 [Accessed 16 August 2020]

Bootsma, M. C., \& Ferguson, N. M. (2007). The effect of public health measures on the 1918 influenza pandemic in U.S. cities. Proceedings of the National Academy of Sciences of the United States of America, 104(18), 7588-7593. https://doi.org/10.1073/pnas.0611071104

World Health Organization. n.d. Naming the coronavirus disease (COVID-19) and the virus that causes it. Available from: https://www.who.int/emergencies/diseases/novel-coronavirus2019/technical-guidance/naming-the-coronavirus-disease-(covid-2019)-and-the-virusthat-causes-it [Accessed 02 August 2020]

Huang, C., Wang, Y., Li, X., Ren, L., Zhao, J., Hu, Y., et al. (2020). Clinical features of patients infected with 2019 novel coronavirus in Wuhan, China. The Lancet, 395 (10223): 497506.

World Health Organization. (2020). Statement on the second meeting of the International Health Regulations (2005) Emergency Committee regarding the outbreak of novel coronavirus (2019-nCoV). Available from: https://www.who.int/news-room/detail/30-01-2020statement-on-the-second-meeting-of-the-international-health-regulations-(2005)emergency-committee-regarding-the-outbreak-of-novel-coronavirus-(2019-ncov) [Accessed 02 August 2020]

World Health Organization. (2020). WHO Director-General's opening remarks at the media briefing on COVID-19-11 March 2020. Available from: https://www.who.int/dg/speeches/detail/who-director-general-s-opening-remarks-at-themedia-briefing-on-covid-19---11-march-2020 [Accessed 02 August 2020]

"COVID-19 Dashboard by the Center for Systems Science and Engineering (CSSE) at Johns Hopkins University (JHU)". ArcGIS. Johns Hopkins University. Retrieved 29 August 2020.

Paul, R. (2020) Bangladesh confirms its first three cases of coronavirus. Reuters 8 March 2. Available from: https://www.reuters.com/article/us-health-coronavirus-bangladeshidUSKBN20V0FS [Accessed 02 August 2020]

Ahsan, N. (2020). The unequal burdens of working from home. The Daily Star, September 08. Available from: https://www.thedailystar.net/opinion/news/the-unequal-burdensworking-home-1957493

Liang, L. (2020). How Covid-19 led to a nationwide work-from-home experiment. BBC 9th March. Available from: https://www.bbc.com/worklife/article/20200309-coronaviruscovid-19-advice-chinas-work-at-home-experiment

Amin, M.A. (2018). Dhaka remains the world's most densely populated city. Dhaka Tribune October 14.

Chermayeff, S. and Alexander, C. (1963). Community and privacy toward a new architecture of humanism [1 st ed.]. N.Y.: Doubleday.

Correa, C. (1989). Urbanisation. In The New Landscape. London: Butterworth Architecture

Bangladesh Bureau of Statistics. (2016). Statistical Pocketbook Bangladesh 2015. Available from: www.bbs.gov.bd

Khan, N. (2008). Study of Morphological Transformation in the Planned Residential Areas of Dhaka City. M.ARCH Thesis, Department of Architecture, Bangladesh University of Engineering and Technology.

Akter, S. \& Chiu, R. (2017). Livability in dense residential neighbourhoods of Dhaka. Housing Studies. 34. 1-22. 10.1080/02673037.2017.1364711.

Hussain, Akbar. (2010). Living in the High-rise Apartments of Dhaka City. Journal of Anthropology. Vol. 31, 131-148. 
Islam, Z.H., (2018). Changes in Shared Spaces for Social Interaction: A Socio-Temporal Evaluation of Real Estate Apartments in Dhanmondi R/A, Dhaka. Protibesh Vol 16, Issue 1. 18-33.

Islam, Z.H. (2012). Making Space Liveable: A Post Occupancy Evaluation of the Spaces for Social Interaction in Apartments of Dhaka. Proceedings of the International Seminar on Livable Space (IsLivas) - 2012: Creating Space for Better Life. 16-17 